\title{
A Flight Test Method of Flammable Liquid Leakage and Discharge for Certain Aircraft
}

\author{
Jiangtao Song ${ }^{1, a}$, Yan Zhao ${ }^{2}$ and $\mathrm{Yu} \mathrm{Li}^{1}$ \\ ${ }^{1}$ Engine Institute, China Flight Test Establishment, 710089 Xi'an, China \\ ${ }^{2}$ General Institute, China Flight Test Establishment, 710089 Xi'an, China
}

\begin{abstract}
To guarantee the successful completion of airworthiness certification test for a certain type of aircraft, the leakage and discharge compliance criteria of flammable liquid were designed by studying airworthiness requirements and the design characteristic of the civil aircraft, where flammable liquid leakage zones and hazardous zones in which liquids are not allowed to enter were determined. Further the test equipments and the dyeing liquor for replacing flammable fluid were developed, and ground and flight test methods were proposed. Moreover, the above test equipment and methods were applied to flight tests of flammable liquid leakage and discharge for certain civil aircraft. The test results show that the test equipment is stable and reliable, and the flight test method can accurately demonstrate the flammable liquid leakage and discharge.
\end{abstract}

\section{Introduction}

Fuel oil, hydraulic oil and other flammable liquids always exist on aircrafts where it is inevitable that these flammable liquids sometimes leak during flights. The airworthiness authorities pay attention to the fire safety of civil aircrafts[1], and require the safety analysis according to the CCAR25 clause. Further it is necessary to demonstratively test the discharge design of the potential flammable liquid leakage area of aircrafts to show the compliance[2]. Boeing and Airbus have carried out some researches on their various civilian passenger and transport aircraft[3]. The available materials show that the leak discharge test method of military aircraft does not meet the requirements of airworthiness. The test method of flammable liquid leakage and discharge is closely related to the aircraft structure and discharge system structure. Thus the method in reference [2] cannot be directly applied to certain specified aircraft. According to the design characteristics of certain aircraft, a flight test method of flammable liquid leakage and discharge for the aircraft was developed. This paper includes the determination of leakage and discharge compliance criteria of flammable liquids, the development of the dyeing liquid and the injection equipment, the flight test method, the application and the test results analysis..

\section{Discharge zones and compliance criterion}

\subsection{Determination of flammable liquid leakage zones}

It is usually believed that single point failures of system pipes or abnormal maintenance activities of accessories could lead to flammable liquids leakage. Thus the potential flammable liquid leakage zones refer to the areas where the pipes and accessories for hydraulic and fuel systems locate and the adjacent areas. Based on above definition and certain civil aircraft design characteristics, the determined flammable liquid leakage areas for test are engine cabin, APU cabin, hanging area, wing-body drum rectifier area and rear equipment tank. Every test zone corresponds to some hazard areas shown in table 1 where flammable liquids are not allowed to enter.

Table 1. Test/discharge zones and hazard/inaccessible zone for flammable liquids

\begin{tabular}{ccc}
\hline No. & $\begin{array}{c}\text { Test/Discharge } \\
\text { zones }\end{array}$ & Hazard/Inaccessible areas \\
\hline 1 & engine cabin & $\begin{array}{c}\text { Power plant intake system, APU } \\
\text { intake and exhaust system, }\end{array}$ \\
\hline
\end{tabular}




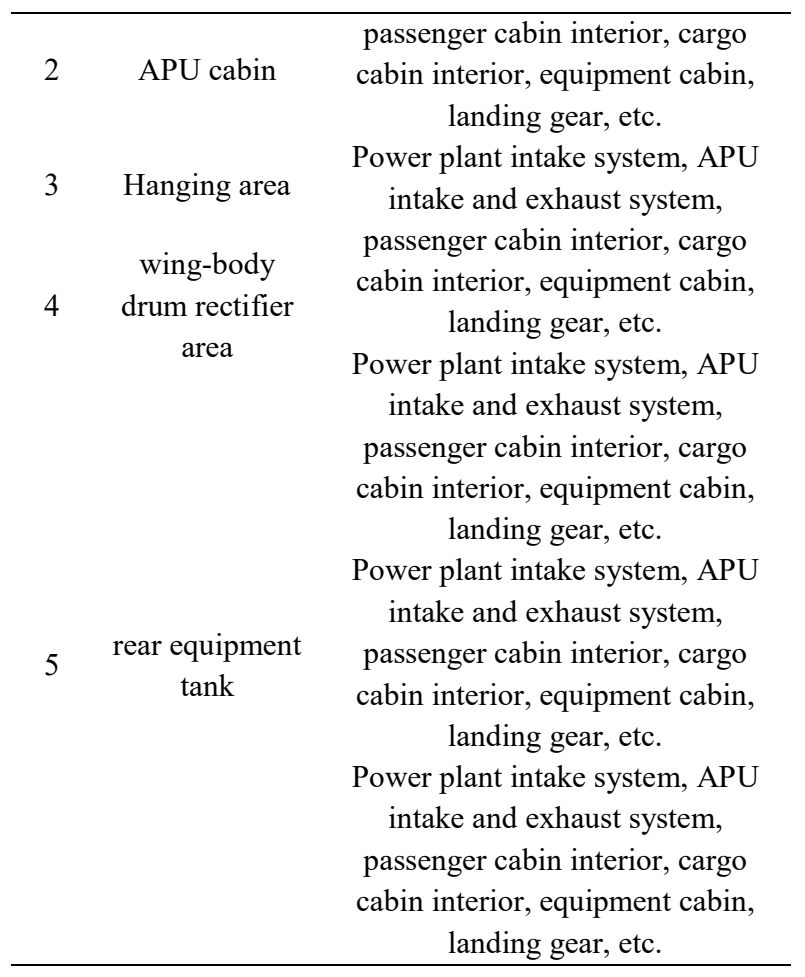

\subsection{Compliance criteria of discharge test}

According to the requirements of airworthiness clause and the design characteristics of certain aircraft, the compliance criteria are as follows.

\subsubsection{Ground test compliance criteria}

More than $90 \%$ of the liquid volume is collected from the drain hole/mouth in the discharge area, and the location of the remaining liquid is explained. The time of liquid collection is $10 \mathrm{~min}$, and the accumulative amount of a single region in the test area is not more than $1.5 \mathrm{oz}$.

\subsubsection{Flight test compliance criteria}

Flammable liquids in the test area can be safely excluded from accumulation and no other risks arise when discharged.

\section{Test dyeing liquid and equipment development}

Before the design of flammable liquid discharge system is proved to be qualified, it is undoubtedly very dangerous to use real flammable liquid to carry out the discharge test, so it is necessary to develop a substitute for flammable liquid in the test to demonstrate the compliance. Leakage usually means the failures of equipments or pipelines. It is obviously high cost to destroy the equipments or the pipelines in test areas artificially. Therefore it is necessary to develop a liquid injection device to characterize the leakage.

\subsection{Dyeing liquid for test}

To ensure test safety and capture the liquid fluidity, the color liquid should be developed instead of the flammable liquid. The substitute must be non-corrosive, easy to adhere to the body surface, easy to scrub, safe and be with low temperature resistance to $-45{ }^{\circ} \mathrm{C}$. Also its flow property is similar to that of aircraft flammable liquid. After a lot of experiments, the dyeing liquid is made of color paste and antifreeze proportionally.

\subsection{Dyeing liquid spray equipment}

The spray equipment is used to spray the dyeing liquid into the test area and measure the dyeing fluid flow quantity. The dye injection device is mainly composed of a DC pump, a liquid storage tank, a flow regulating valve, an electrical control system, a flow measuring instrument, a timer and so on. Two cabinets are designed for storage tank and instrument operations, which can be tested in three test areas at the same time. Figure 1 show the test equipment installed in the cockpit.

\section{Flight test demonstration method for flammable liquid leakage and discharge}

\subsection{Ground test method}

The ground tests mainly focus on the discharge capacity of the discharge holes. By injecting a certain amount of clear water into the test areas, it is verified if the water can be safely discharged without accumulation under the ground condition, and that there will be no other danger when discharged.

\subsubsection{Ground engine-off condition}

The aircraft is stationary on the ground with the engine off. Clear water is injected respectively into every test zone with the dye injection device. The reasonable locations should be selected to collect the fluids discharged outside the body. Also the collection time is recorded. A number of locations should be selected to ensure that the test results are adequate. 


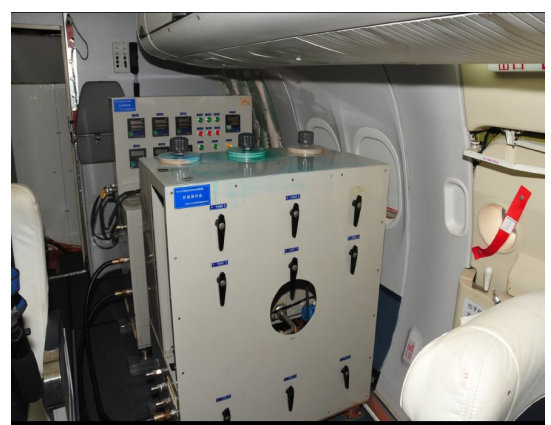

Figure 1. Dyeing liquid ejector

\subsubsection{Ground engine-on condition}

Two additional ground tests are added for engine power plants and APU test zones. Under the condition that aircraft stands still at ground with engine working in slow strain, a certain amount of dyeing liquids are sprayed into engine power plants test area with the dye injection device. Also Under the condition that aircraft stands still at ground with APU working, a certain amount of dyeing liquids are respectively sprayed into APU test area with the dye injection device.

After the tests, the liquid accumulations are checked in the two test area, and the flow paths of the dye solution are observed to verify whether enter the dangerous areas mentioned in Table 1.

\subsection{Flight tests of flammable liquid substitute leakage and discharge}

\subsubsection{Flight test conditions}

Flight test points include routine flight conditions such as taxiing, take-off, climbing, cruising, slow-vehicle descent, approaching leveling, landing with backthrust and landing without backthrust as well as emergency descent, sideslip, hovering and other flying conditions that may cause flammable liquids to be discharged into dangerous areas.

The fly heights with serious air convection are chosen to verify the discharge capacity under the harsh conditions. Clear and cloudless weather conditions should be chosen to prevent the water in the cloud scouring the dyeing to change the flow paths on airframe surface.

\subsubsection{Flight test steps}

(a) Each flight test can be carried out in two test areas, requiring that the liquid discharge from the two test areas do not interfere with each other, and that different coloring liquids are selected.

(b) Before flight test, aircraft test areas and the areas through which the flammable liquid may flow are cleaned to clearly show the flow path of the flammable liquid substitute. Then take photos of test areas and dangerous areas.

(c) After stable flight at the test point, the dye injection device is operated to spray the dye liquid into the test areas for 30 to 60 seconds. After injection, fly normally for 5 minutes to allow plenty of time to discharge excluding landing and taxiing conditions.

(d) At the end of the flight, the dyeing liquid flow path on airframe surface is first photographed. Second the hatches of test areas are opened, the internal flow pattern is photographed, and the dyeing liquid accumulation is checked. Third the dangerous areas are checked to determine if any stained liquid enters and photographs of dangerous areas are taken.

\section{Application and test result analysis}

The test equipment and test method in part 3 and 4 were applied to flight tests of a certain civil aircraft to verify the compliance of flammable liquid leakage and discharge system design.

More than 30 flight tests show that the flow rate of the dyeing injection device is stable and does not interfere with other systems on aircraft, and it can accurately adjust the flow rate and measure the instantaneous flow rate and the cumulative flow rate of the dye liquid in real time.

Some unreasonable system designs were found by comparing the test results with the compliance criteria in part2. Further some system design were corrected and improved to satisfy the compliance criteria.

During the initial APU ground test, liquid leakage was found at the lock buckle of APU hatch. The discharged liquid spatter area is very large and even entered the ventilator of the rear equipment tank, which does not conform to the criteria of part 2.2.1. The initial discharge design of APU has been changed to meet the criterion in part 2.2.1.

During flight demonstration tests in hanging areas, the dyeing liquid entered the exhaust device of APU showed in Figure 2(a) which is dangerous. Then the design was modified to meet the criteria of part 2.2.2. The flight test result after correction was shown in Figure 2(b).

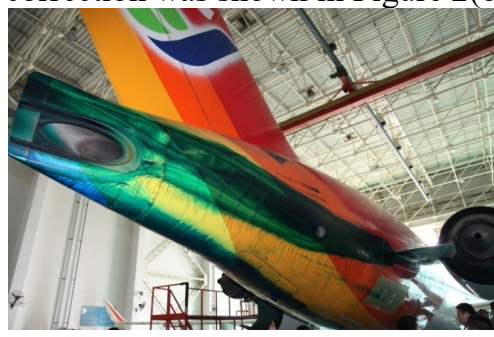

(a) Initial discharge result 


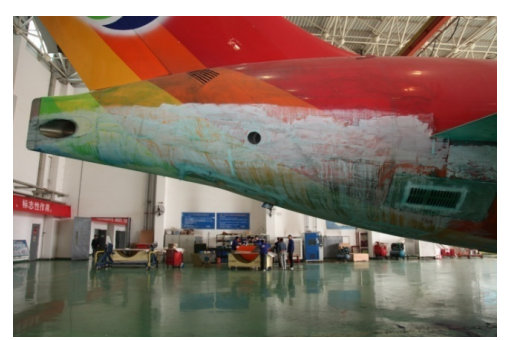

(b) Modified discharge result

Figure 2. Comparison between initial and modified discharge in hanging areas

\section{Conclusions}

The test results show that this method can accurately demonstrate the flammable liquid leakage and discharge of certain aircraft and meet the requirements of airworthiness terms for ground and flight tests of the discharge system in the flammable liquid leakage zone.
The determinations for test zones and inaccessible hazard zones of flammable liquid substitute discharge of a certain aircraft are reasonable. And the developed dyeing liquid can simulate flammable liquid flows accurately. In addition the work of the developed dyeing liquid injection device is stable.

\section{References}

1. Q. S. Zhang , H.P. Qi, C.H. Yang et al. Study on Performance-based Fire Protection Design Method for Aircraft Cabin. Science Technology and Engineering, 2014; 14(28): 311-315

2. CCAR-25-R4. Airworthiness standards for transport category airplanes. 2011-05-14

3. FLAMMABLE FLUID FIRE PROTECTION.AC 25.863-1 draft. U.S.D department of Transportation; Federal Aviation Administration. ANM 